\title{
¿MAYORIA DE EDAD DE LA REVISTA COLOMBIANA DE EDUCACION?
}

Con la presente edición, la Revista Colombiana de Educación llega a su número 25. Su primera salida data de junio de 1978, y desde entonces ha venido entregando regularmente a sus lectores el fruto de sus esfuerzos analíticos. Desde un comienzo se propuso difundir lo mejor de la investigación educativa nacional, campo que mostraba algunos progresos por los años setenta. Economistas, sociólogos, historiadores y diversos estudiosos de las áreas más aplicadas de la educación, habían logrado acumular un volumen de experiencias que legitimaban la fundación de una publicación periódica. Había además un creciente interés en las esferas políticas y en los organismos de decisión del Estado por el papel de la educación en la productividad, la distribución de los ingresos y la democratización social. Los proyectos de reforma emanados del Ministerio de Educación se sucedían unos a otros y los documentos de las oficinas de planificación se multiplicaban al lado de los planes de desarrollo auspiciados por los presidentes de la República. La educación parecía ocupar un lugar estratégico en la modernización del país y los centros de investigación no desaprovechaban las consultorías que circulaban por los organismos internacionales.

Como se esperaba, la institución llamada a coordinar estas labores era la Universidad Pedagógica Nacional. Es una institución pública, su función prioritaria es la formación de docentes, y como lo sugiere su nombre, su punto de referencia es el país. La Revista buscó llevar estos anhelos nacionales al campo de la ciencia y desde un principio se propuso difundir los mejores trabajos de los investigadores locales y extranjeros, además de las corrientes y perspectivas teóricas más significativas en materia de educación. Tradujo estudios publicados originalmente en otros idiomas, rescató documentos coloniales, del siglo XIX y comienzos del XX, divulgo papeles del Estado, reseñó libros, eventos académicos, proyectos de investigación en marcha y promovió debates acerca de los temas del momento. Quería hacer de la educación un objeto de investigación permanente en el cual confluyeran las más diversas disciplinas y perspectivas analíticas. La suma de estos esfuerzos comprendían la extensión de sus logros y de sus fracasos, de sus frustraciones y alegrías*.

Ante los tradicionales énfasis retóricos y valorativos de los medios pedagógicos, la Revista afirmé desde un principio la perspectiva de las ciencias positivas. Trató de mostrar que la investigación en el campo de la educación no escapa al empleo riguroso de datos ligados a marcos de referencia que les confieran sentido y los relacionen con las demás dimensiones de la vida social y cultural. El comité de redacción de la Revista sabía que la educación - como la política - es el campo abonado del punto de vista, del parecer y la opinión. Es el terreno de lo imperfecto y de lo inacabado, de la diversidad y la fragmentación, y al ser la institución encargada de formar las futuras generaciones, los hombres y las mujeres consignan en ella las imágenes más queridas del futuro de la sociedad. Ello es lo que hace que en su interior sea muy difícil diferenciar lo que es de lo que debería ser, pues los actores tienden a ver en la escuela el origen de los males sociales y en sus proyectos de reforma, que son múltiples según los intereses y grupos

\footnotetext{
* Con el mismo nombre de Revista Colombiana de Educación circulé entre 1959 y 1960 una publicación del Ministerio de Educación Nacional. Este esfuerzo no tuvo sin embargo mayor continuidad. Apenas se publicaron siete números con un marcado acento en las discusiones pedagógicas, no obstante que algunos artículos y notas informativas dejaban ver ya un interés inicial por la sociología de la educación y las relaciones entre educación y desarrollo económico, los campos más cultivados por la investigación educativa durante los años sesenta.
} 
sociales en pugna, la fuente de la felicidad y de la prosperidad de los pueblos. En los predios del magisterio y de sus instituciones, las Escuelas Normales y las Facultades de Educación, se ha difundido con prodigioso éxito esta forma de aproximación al aparato educativo. Allí un observador desprevenido encuentra que el ambiente intelectual de una discusión de educadores no está muy lejos del clima de una reunión de padres de familia. La Revista, auspiciada por una institución pedagógica, se enfrenté con esta arraigada forma de ver los fenómenos educativos. A muchos usuarios, tanto lectores como autores de trabajos, se les hacía muy difícil acercarse al estudio de la escuela sin imágenes preconcebidas. Partían del supuesto de que el sistema educativo andaba mal y que era necesario sugerir reformas, pero nunca se encontraban con la necesidad de describir con algún rigor lo que se deseaba transformar.

Frente a este arraigado estilo cognitivo hallé otro no exento de dificultades. En la investigación educativa es fácil reunir información cuantitativa —costos, matrícula, volumen de maestros, número de escuelas, etc. Los escollos surgen sin embargo cuando se intenta ligar la evolución de estos guarismos con la dinámica más general y amplia de la sociedad en medio de la cual se mueven. Los números nada o poco dicen si no están apresadas por conceptos y marcos de referencia que sugieran su ordenamiento y el sentido de su lectura. Esto ocurre con frecuencia en los centros de investigación privados que manejan datos cuantitativos relativamente amplios y donde los investigadores - que muchas veces son meros técnicos en recolección de información- no disponen del tiempo necesario para meditar sobre la posible riqueza analítica de las cifras que tienen a mano. Allí los investigadores trabajan a destajo y siempre se encuentran apurados ante las demandas de la sobrevivencia y las urgencias asociadas con la entrega de los documentos finales a las entidades patrocinadoras. Esto hace que de sus modernos procesadores de palabras salgan informes de investigación como palomas y conejos de la manga de un prestidigitador.

En medio de estos dos estilos de investigación, fue surgiendo un tercer énfasis caracterizado por un marcado acento teórico con escasa sensibilidad empírica. Tiende a expresarse en discursos cerrados ajenos a toda ejemplificación y uso de casos como fuente de ilustración. Sus autores, la mayoría de ellos con algún interés filosófico, buscan aplicar a los problemas de la educación, con más entusiasmo intelectual que dominio conceptual, la obra de un renombrado pensador del momento -Piaget, Foucault, Popper, Habermas, etc. Aunque parece asistirlos un deseo de renovar los estudios educativos, sus resultados son todavía muy limitados y buena parte de sus productos no logran superar los textos espesos y de difícil lectura de poca utilidad para la comprensión de los problemas concretos.

Estos estilos dominantes no son exclusivos de Colombia. Algo similar ocurre en los demás países de América Latina donde ha existido algún interés por los estudios educativos. Allí la investigación en educación ha sufrido de una especie de anorexia metodológica, de desgano por la teoría y los datos, por la equilibrada relación entre las observaciones y los instrumentos analíticos. Parece que su materia se resistiera a la observación desapasionada y que sus analistas rechazaran todo intento de asimilar las experiencias acumuladas por las disciplinas con mayor tradición en investigación. Al campo lo rodea además una constelación de factores negativos: falta de recursos, fragilidad de los centros de investigación, ausencia de continuidad en los estudios, una afirmada tradición discursiva en las instituciones pedagógicas y un escaso interés de los investigadores más capacitados de la región por los temas vinculados con la enseñanza. 
Es un área nueva, subordinada a muchas otras, de escaso prestigio y sin muchos antecedentes que fijen sus rumbos y patrones adecuados.

La Revista no siempre logró evadir estas limitaciones. Si deseaba reflejar los esfuerzos de investigación debía consignar en sus páginas los productos del medio que llenaban algunos requisitos de calidad y pertinencia. $Y$ si bien su cuerpo de redacción compartió desde un principio unos criterios mínimos respecto de los trabajos a publicar coherencia interna y control de los juicios de valor- no siempre conté con el número suficiente de materiales para dar a luz ejemplares de excelencia. Además, la institución que la ha auspiciado durante estos años - con fervor unas veces y con benevolencia otras - no tiene todavía la capacidad de alimentar una parte significativa de sus páginas. Los docentes de la Universidad Pedagogica Nacional no han logrado afirmar la investigación como algo normal y cotidiano y su Centro de Investigaciones es aún muy limitado.

En el desarrollo de estas labores la Revista se encontró con una dificultad adicional. Si al comienzo de sus tareas había un grupo de personas dedicadas a los estudios educativos, a mediados de la década del ochenta la investigación en el área disminuyó considerablemente. Los esfuerzos empíricos de los años anteriores se estancaron y a su comité de redacción empezaron a llegar "refritos", trabajos meramente especulativos basados en comentarios y variaciones incidentales sobre temas ya conocidos. Ante esta situación tomó su mirada hacia otros países de América Latina, pero a poco encontró que allí ocurría algo semejante. Fue entonces cuando hizo la decisión de "educar a los educadores", de difundir textos clásicos para nutrir la teoría y los marcos de referencia. Tradujo ensayos de Emile Durkheim y de Max Weber no conocidos en castellano, y vertió trabajos de los franceses Pierre Bourdieu y Henri Giroux, de los ingleses Basil Bernstein y Rod Watson y de los norteamericanos Frank $\mathrm{H}$. Bowles y Erwin Epstein. A ello sumé la divulgación de antiguos trabajos sobre la educación colombiana elaborados en el extranjero y apenas conocidos en nuestro medio. Así buscaba ofrecer realizaciones concretas y ejemplos dignos de ser seguidos en el zigzagueante campo de la investigación educativa. Esto le confirió a la Revista nuevos aires y una postura más amplia donde lo nacional iba de la mano de las contribuciones internacionales más festejadas.

¿Qué áreas han aparecido con más frecuencia en sus páginas? Como se desprende de lo anterior, las contribuciones de las ciencias sociales fueron las más constantes. La historia, la sociología y la economía de la educación han sido las disciplinas más sensibles a la investigación, y aunque los estudios pedagógicos y sus diversas vertientes -las didácticas - han ocupado varias veces las páginas de la Revista, aquí la producción no presenta el volumen y la calidad que era de esperar cuando se tiene en cuenta el número de docentes y de instituciones dedicadas a los problemas de la enseñanza. La producción en estas áreas tiene aún que enfrentar la callada resistencia de un pasado retórico poco afín al estilo de trabajo de las ciencias positivas. Y la psicología, una disciplina que supera a los graduados de cualquier otra especialidad de las ciencias humanas, desde hace varios lustros se ha refugiado en el ejercicio profesional —en la docencia, el consultorio y la clínica- y ha olvidado las labores de investigación tan caras a sus colegas de Europa y los Estados Unidos.

No obstante las dificultades anotadas, el autor de estas líneas, que ha tenido la oportunidad de participar en el comité de redacción de la Revista desde su fundación, encuentra que el balance final es positivo. Si la publicación nació cuando la investigación en educación mostraba algún desarrollo, no cabe duda que ella contribuyó a organizar el 
campo y a hacerlo mucho más claro y específico. Al crear un órgano que le diera expresión y apoyo, le confirió autonomía como área de estudio, y si bien no ha monopolizado la difusión de los materiales en educación, pues otras revistas del país también lo hacen, las evaluaciones que se emprendan en el futuro encontrarán aquí sus fuentes más sistemáticas y acabadas. Como toda publicación periódica, sus entregas presentan desniveles: tiene en su haber números buenos, algunos excelentes y otros regulares. Tal vez ello exprese lo que realmente ha estado sucediendo en el escenario de la investigación educativa nacional.

Estos esfuerzos ininterrumpidos sugieren una mayoría de edad de la Revista, pero no una madurez exenta de peligros. El campo es aún inestable y susceptible de serios reveces. La producción en educación no ha logrado todavía afirmarse, los Centros de Investigación son débiles y la continuidad de los proyectos es bastante precaria. Pero a pesar de estos vacíos la Revista Colombiana de Educación ha estado allí para registrar sus mejores productos. No debemos olvidar finalmente, que este paciente trabajo se debe a la Universidad Pedagógica Nacional, la institución que a lo largo de estos años ha patrocinado su presencia en los medios intelectuales.

Gonzalo Cataño Universidad Pedagógica Nacional 